\title{
Structural and mechanical properties of asphalt mixtures - basis for rationing of their technological properties
}

\author{
E.V. Kotlyarskiy \\ Road-building Materials chair \\ Moscow automobile and road state technical university (STU- \\ MADI) \\ Moscow, Russia \\ eco46@mail.ru \\ S. Yu. Andronov \\ Transport construction chair \\ Saratov state technical University named \\ after Y. A. Gagarin \\ Saratov, Russia \\ atomic08@yandex.ru \\ Kadyrov Zh. N. \\ Transport equipment and standardization chair \\ Kazakh University of railway engineering \\ Almaty, Republic of Kazakhstan \\ kadyrov.1954@mail.ru
}

\begin{abstract}
The article is devoted to the forecast and evaluation of the quantitative requirements for mechanical and structural-mechanical properties of asphalt concrete in the production stage.

The results obtained can be useful for developers of asphalt mixing and compacting machinery for road construction and public works.
\end{abstract}

Keywords - Bitumen, control, test, certification, standard, heterogeneity, measurement

\section{INTRODUCTION}

The constant change in operating conditions of asphalt concrete pavements, associated with increased traffic intensity, increased axle loads, speed regime, weather and climatic influences and other factors every 10-15 years, requires the use of new bituminous mineral materials in the pavement construction with increased transport-operational properties $[1,6]$.

This is evidenced by the continuous improvement of the regulatory framework of technical requirements for asphalt concrete in our country.

GOST 9128, first approved in 1954, underwent fundamental changes in 1965 (normalized low-temperature properties), 1974, 1984, 1997, 2009, and finally in 2013. There have been attempts to use and introduce advanced

\author{
V.I. Kochnev \\ Road-building Materials chair \\ Moscow automobile and road state technical university (STU- \\ MADI) \\ Moscow, Russia \\ eco46@mail.ru \\ Yu. Em. Vasiliev \\ Road-building Materials chair \\ Moscow automobile and road state technical university (STU- \\ MADI) \\ Moscow, Russia \\ vashome@yandex.ru \\ A. V. Kochetkov \\ Road faculty \\ Perm national research polytechnic university \\ Perm, Russia \\ soni.81@mail.ru
}

foreign experience (for example, EN and Superpave standards).

Analysis of the experience shows that both domestic and foreign standards do not regulate the requirements for the technological properties of asphalt concrete.

It is known that asphalt mixes and asphalt concretes have different characteristics according to the classifications accepted in Russia and abroad, and the technique used for the production of the work has significant differences in technological possibilities when laying and compacting asphalt mixtures in structural layers of nonrigid road topping [3].

When developing projects for the production of works for specific facilities, specialists of contractors must, based on standard technological solutions, additionally take into account natural and climatic factors, weather conditions, logistics when delivering the asphalt-concrete mixture from the ABZ to the site of piling, features of the pavement design, and a lot of other less significant factors, as a consequence of which the adoption of optimal technological schemes entirely depends directly on the concrete deleterious producer works.

From what has been said above, it follows that the entire final technological cycle, on which the formation of the structure and properties of asphalt concrete basically depends, depends entirely on the qualifications and experience of the contractor. 
Experience in the construction of asphalt concrete pavements and foundations indicates that the technology is not always optimal, which ultimately affects the lifetime of the entire road structure.

The formation of the optimal structure and properties of a complex composite polydispersed polymineral material based on organic binders with complex non-linear rheological properties cannot occur with non-optimal technological parameters at the stage of mixing in asphalt mixing plants, during the delivery of the mixture, its packing and compaction [5].

\section{THE CHOICE OF MATHEMATICAL MODEL}

It should be taken into account that the technological equipment has various design features and energy capabilities, and also the conditions for the production of road works and designs of asphalt-concrete layers and underlying underlying layers of the base on roads of various categories may differ substantially:

$$
P_{m}=k_{1} \cdot F_{c} \cdot n^{2 / 3}=k_{2} \cdot F_{c} \cdot \varphi \cdot S_{y d}^{2}=k_{3} \cdot F_{c} \cdot \varphi \cdot \delta_{i}^{-2},
$$

where:

$P_{m}$ - yield value, $P a$;

$F_{c}-$ average adhesion force in contact between particles, $\mathrm{H}$;

$n-$ the average number of contacts per unit volume $\left(\mathrm{cm}^{3}\right)$;

$\varphi_{1}$ - relative density;

$\mathrm{S}_{\mathrm{sp}}$ - specific surface area of the mineral part, $\mathrm{cm}^{2} / \mathrm{g}$;

$\Delta_{e q}$ - equivalent (weighted average) particle size of the dispersed phase.

The average number of unit contacts per unit volume by [1] is determined by formula (2):

$$
n=6,7373 \cdot e^{5,44 \cdot \varphi} \cdot \delta_{i}^{-2}
$$

Based on theoretical and experimental studies [2], it has been established that asphalt-concrete mixtures and asphaltconcrete in various technological and operational situations can be considered as a highly concentrated dispersive system whose properties largely depend on the physical and chemical processes that occur when the material structure is formed.

The evaluation of these processes must be carried out taking into account the basic laws of physical and chemical mechanics and the specifics of contact interactions $[1,2]$.

The main regularities were established in the works of academician P.A. Rebinder and his students on different model compositions (2):

$$
\begin{gathered}
F_{c}=P_{m} \cdot \delta^{2} \cdot \frac{\rho^{\prime}}{\rho_{n}} \cdot \frac{\left(1-\varphi_{i}\right) \cdot\left(1-\varphi_{p}\right)}{\left(\varphi_{i}-\varphi_{p}\right)}, \\
P_{i}=\frac{F_{c}}{S_{i}}=\frac{P_{m}}{n^{1 / 3}}
\end{gathered}
$$

$$
P_{m}, F_{c}, n, \delta_{e q} \text { - the same as in formula (1), }
$$

$\varphi$ - the relative density of the dispersed phase (achieved as a result of technological influences and in an absolutely destroyed - loose state,

$\rho^{\prime}-$ density of dispersed phase particles and $\rho_{n}$ - density of asphalt concrete.

Without analysis of the processes of formation of bituminous mineral material under the influence of technological factors, it is impossible to explain the processes of structure formation and structural failure during operation in constructive layers of pavement.

The methods of designing asphalt-concrete mixtures with the required structural-mechanical properties, which is implemented on a computer, are described in [2,4].

The formation and destruction of the asphalt-concrete mixture and asphalt-concrete structure at various technological stages are shown in Fig. 1. 


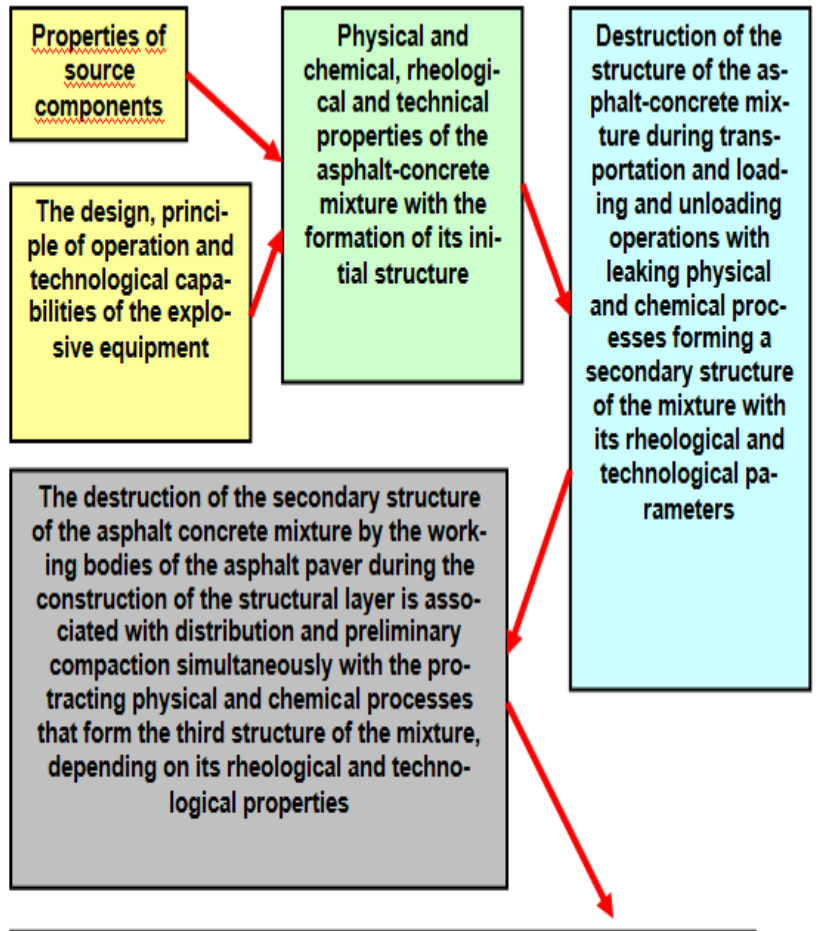

Repeated destruction and formation of the structure of a hot asphalt-concrete mixture with sealing effect of the link of road rollers with constantly changing structural and mechanical characteristics of the compacted mixture and compacted asphalt concrete. asphalt paver working in the process of the device. At the same time, the structuring physicochemical processes at the interface "bi-tumstone material" continue with the formation of the micro-, meso- and macrocontact structure of the bituminous mineral mixture until the final structure of the compacted hot asphalt concrete is reached.

The final formation of the structure of the cooling asphalt-concrete layer with continuing structuring physico-chemical processes at the interfaces with formation of micro-, meso- and macrocontact structure of bituminous mineral material with optimal (or close to optimal) asphalt-concrete structure providing the required complex of building and technical properties, guaranteeing reliable operation of the asphalt-concrete structural layer during the required service life.

Fig. 1. Formation and destruction of asphalt-concrete mixture and asphaltconcrete structure at various technological stages

To analyze the changes in the limiting values of structural and mechanical properties of asphalt concrete, the requirements for standardized GOST 9128 indices of physical and mechanical properties for different types and types of asphalt concrete I, II and III grades for all road and climatic zones of the Russian Federation were used.

They are the compressive strength at $50{ }^{\circ} \mathrm{C}$ and test speeds of 3 and $50 \mathrm{~mm} / \mathrm{min}\left(R_{50}{ }^{3}, R_{50}{ }^{50}\right)$, tangent of the angle of internal friction $(\operatorname{tg} \varphi)$ and adherence $(c)$.
These requirements depend on the extreme summer operating temperature (road and climatic zone), which in turn is due to the choice of the viscous road bitumen grade in accordance with GOST 22245, the content of crushed stone or the type and grade of asphalt concrete, which is determined by the purpose of the road and the designation of the structural pavement layer.

Requirements for the mechanical properties of asphalt concrete at $50{ }^{\circ} \mathrm{C}$ (compressive strength, tangent of the angle of internal friction and adhesion) vary.

Using Coulon's formula (5), the values of the limiting shear stress were found according to expressions (2) and (4), the limiting values of the average cohesion strength in contact between particles and the average strength of a single contact:

$$
P_{m}=R_{50} \cdot \operatorname{tg} \varphi+c \text {, }
$$

where:

$R_{50}$ - compressive strength at temperature of $50{ }^{\circ} \mathrm{C}$ and a deformation rate of $50 \mathrm{~mm} / \mathrm{min}$,

$\operatorname{tg} \varphi$ - tangent of the angle of internal friction,

$c$-adherence.

To obtain the dependence of the ultimate shear stress on the compressive strength at $50{ }^{\circ} \mathrm{C}$ and the test speed of 50 $\mathrm{mm} / \mathrm{min}$, all the calculated values obtained in expression (5) and the standard values of the tensile strength at $50{ }^{\circ} \mathrm{C}$ for all asphalt concrete grades in all road climatic zones were processed on a computer using correlation regression analysis by linear, power, logarithmic and exponential mathematical dependencies.

Preference was given to the regression of the most simple linear relationship, having the accuracy and adequacy required (6):

$$
P_{m}^{50}=b_{1} \cdot R_{50}+b_{0}
$$

where:

$b_{0}$ and $b_{1}-$ regression coefficients.

The regression coefficients and multiplication coefficients obtained for the asphalt-concrete I, II and III brands are shown in Table. 1.

TABLE I. REGRESSION COEFFICIENTS AND MULTIPLE CORRELATION

\begin{tabular}{|c|c|c|c|}
\hline \multirow{2}{*}{$\begin{array}{l}\text { Brands } \\
\text { of } \\
\text { asphalt } \\
\text { concrete }\end{array}$} & \multicolumn{2}{|c|}{ Coefficients of regression } & \multirow{2}{*}{$\begin{array}{l}\text { Coefficient } \\
\text { of } \\
\text { multiple } \\
\text { correlation }\end{array}$} \\
\hline & $b_{0}$ & $b_{1}$ & \\
\hline I & 0.1365 & 0.994 & 0.9772 \\
\hline II & 0.1357 & 0.9857 & 0.9818 \\
\hline III & 0.1258 & 0.996 & 0.9466 \\
\hline
\end{tabular}
COEFFICIENTS FOR I, II AND III BRANDS OF ASPHALT CONCRETE 
Analytical expressions of the obtained dependences for different brands in different road-climatic zones have similar regression coefficients and high coefficients of multiple correlation.

\section{LABORATORY STUDY}

The realization of the dependences obtained allowed us to formulate the requirements for the ultimate shear stress at the test temperatures normalized in GOST 9128, which are shown in Table. 2.

TABLE II. REQUIREMENTS FOR THE ULTIMATE SHEAR STRESS (PM)

\begin{tabular}{|c||c|c|c|}
\hline \multicolumn{1}{|c||}{} & \multicolumn{3}{|c|}{$\begin{array}{c}\text { Ultimate } \\
\text { shear } \\
\text { stress, } \\
\text { MPa, }\end{array}$} \\
\cline { 2 - 4 } $\begin{array}{c}\text { Test } \\
\text { temperature, } \\
{ }^{\circ} \mathrm{C}\end{array}$ & \multicolumn{3}{|c|}{$\begin{array}{c}\text { Brand of } \\
\text { asphalt } \\
\text { concrete }\end{array}$} \\
\cline { 2 - 4 } & 1 & 2 & 3 \\
\hline 0 & $<8$ & $<9$ & $<10$ \\
\hline 20 & $>3.0$ & $>3.5$ & $>4.0$ \\
\hline 50 & $>1.0$ & $>1.0$ & $>1.0$ \\
\hline
\end{tabular}

Great practical interest may be derived from the prediction of the change in compressive strength and yield value in a wide range of operating and process temperatures shown in Fig. 2.

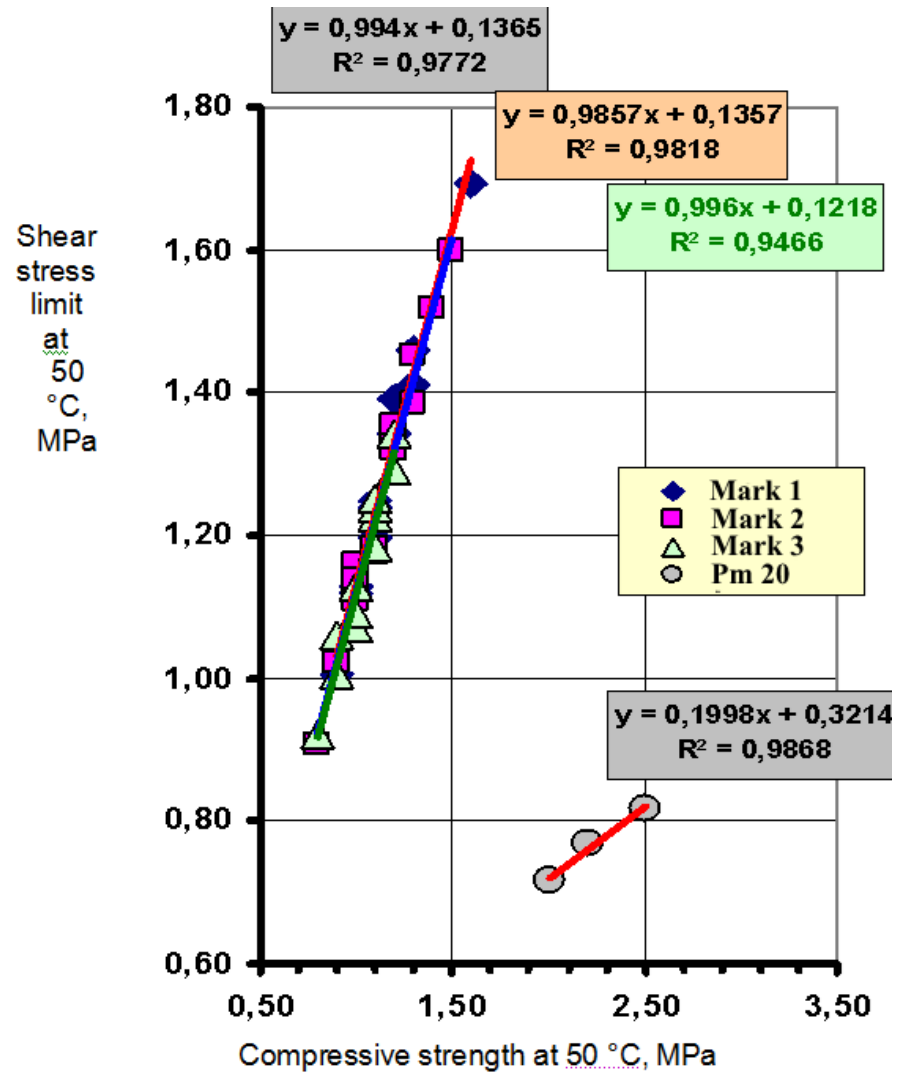

Fig. 2. Change in the ultimate shear stress as a function of the compressive strength at $50{ }^{\circ} \mathrm{C}$

The operating temperature can be referred to as an interval between $-20{ }^{\circ} \mathrm{C}$ and $+50{ }^{\circ} \mathrm{C}$, technological temperatures - from $+80{ }^{\circ} \mathrm{C}$ to $+160{ }^{\circ} \mathrm{C}$, which shows exponential regression models of the change in compressive strength versus test temperature.

Analysis of the dependencies allows us to formulate the conclusions that regression coefficients with an increase in the brand of asphalt decrease, which indicates a lower temperature sensitivity of brand I of asphaltic concrete.

The results of calculations for determining the change in the indicated mechanical and structural-mechanical parameters for different grades of asphalt concrete in various roadclimatic zones are given in Table. 3.

The analysis of the obtained results allowed formulating quantitative requirements for the mechanical and structural mechanical properties of asphalt-concrete mixtures at the technological stages of compaction (Table 3) and mixing (Table 4). 


\section{RESULTS AND DISCUSSION}

TABLE III. FORECAST OF MECHANICAL PROPERTIES

\begin{tabular}{|c|c|c|c|c|c|c|c|c|c|c|c|c|}
\hline \multirow{3}{*}{ 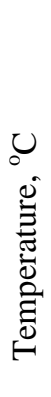 } & \multicolumn{6}{|c|}{ Brand of asphalt } & \multicolumn{6}{|c|}{$\begin{array}{c}\text { Road and } \\
\text { climatic zone }\end{array}$} \\
\hline & 1 & 2 & 3 & 1 & 2 & 3 & I & $\begin{array}{l}\text { II, } \\
\text { III }\end{array}$ & \begin{tabular}{|c}
$\mathrm{IV}$, \\
$\mathrm{V}$
\end{tabular} & I & \begin{tabular}{|l} 
II, \\
III
\end{tabular} & $\begin{array}{c}\text { IV } \\
\text { V }\end{array}$ \\
\hline & $\begin{array}{r}\text { Con } \\
\text { st }\end{array}$ & $\begin{array}{l}\text { npres } \\
\text { rengt } \\
\mathrm{MPa}\end{array}$ & $\begin{array}{l}\text { sive } \\
\text { h, }\end{array}$ & & $\begin{array}{l}\text { Yield } \\
\text { value } \\
\mathrm{MPa}\end{array}$ & & $\begin{array}{r}\text { Con } \\
\text { st }\end{array}$ & $\begin{array}{l}\text { npres } \\
\text { rengt } \\
\mathrm{MPa}\end{array}$ & $\begin{array}{l}\text { sive } \\
\text { h, }\end{array}$ & & $\begin{array}{l}\text { Yield } \\
\text { value, } \\
\text { MPa }\end{array}$ & \\
\hline-20 & 18.1 & 21.5 & 25.2 & 18.1 & 21.4 & 25.2 & 6.06 & 7.26 & 9.15 & 10.2 & 12.5 & 16.3 \\
\hline-10 & 11.8 & 13.8 & 15.8 & 11.9 & 13.7 & 15.8 & 4.31 & 5.08 & 6.24 & 6.86 & 8.3 & 10. \\
\hline 0 & 7.68 & 8.82 & 9.88 & 7.77 & 8.82 & 9.96 & 3.07 & 3.55 & 4.25 & 4.64 & 5.5 & 6.76 \\
\hline 20 & 3.26 & 3.61 & 3.88 & 3.38 & 3.7 & 3.98 & 2.0 & 2.20 & 2.5 & 2.0 & 2.23 & \\
\hline 50 & 0.9 & 0.95 & 0.95 & 1.03 & 1.07 & 1.07 & 0.6 & 0.65 & $\mid 0.7$ & 0.71 & 0.78 & 0.86 \\
\hline 140 & 0.02 & 0.02 & 0.01 & 0.16 & 0.15 & 0.14 & 0.03 & 0.02 & 0.02 & 0.0 & 0.02 & \\
\hline 160 & 0.01 & 0.01 & 0.01 & 0.14 & 0.14 & 0.13 & 0.01 & 0.01 & 0.01 & 0.0 & 0.01 & \\
\hline 160 & 0.01 & 0.01 & 0.01 & 0.01 & 0.01 & 0.01 & 0.02 & 0.02 & 0.01 & 0.02 & 0.02 & \\
\hline 175 & 0.0 & 0.0 & 0.0 & 0.0 & 0.0 & 0.0 & 0.01 & 0.01 & 0.01 & 0,005 & 0.004 & 0.00 \\
\hline
\end{tabular}

The obtained values make it possible to more reasonably develop technological schemes for the preparation of asphaltconcrete mixtures at asphalt plants, taking into account the capabilities and technical parameters of the asphalt mixing plants, taking into account their design features and energy capabilities.

Managing the technological processes can change the temperature of the preparation of the mixture and varying the duration of mixing in batch mixers or the rate of supply of raw materials - continuous.

TABLE IV. REQUIREMENTS FOR TECHNOLOGICAL PROPERTIES OF ASPHALT CONCRETE MIXTURES DURING COMPACTION

\begin{tabular}{|l|l|l|}
\hline & $\begin{array}{l}\text { Durability, } \\
\mathrm{kPA}\end{array}$ & $\begin{array}{l}\text { Yield } \\
\text { value, } \\
\mathrm{kPA}\end{array}$ \\
\hline $\begin{array}{l}\text { Start of } \\
\text { compaction }\end{array}$ & 90 & 220 \\
\hline $\begin{array}{l}\text { End of } \\
\text { compaction }\end{array}$ & 250 & 390 \\
\hline
\end{tabular}

TABLE V. REQUIREMENTS FOR TECHNOLOGICAL PROPERTIES OF ASPHALT CONCRETE MIXTURES WITH STIRRING

\begin{tabular}{|l|l|l|}
\hline & $\begin{array}{l}\text { Durability, } \\
\text { kPA }\end{array}$ & $\begin{array}{l}\text { Yield } \\
\text { value, } \\
\mathrm{kPA}\end{array}$ \\
\hline Start of mixing & 10 & 10 \\
\hline End of mixing & 20 & 20 \\
\hline
\end{tabular}

\section{CONCLUSION}

When developing the sealing technology in the production projects, it is necessary to implement a more multifactorial non-stationary task taking into account the weather and climate conditions, the range of mixture transportation, the composition, mass parameters and type of sealing machines in the road roll link, the sequence of their movement on the microgrip, the number of passes along one track and much more.

\section{References}

[1] E.V. Kotlyarskiy, V.N. Finashin, N.B. Uryev, V.E. Chernomaz, "Formation of the structure of highly concentrated disperse materials, taking into account contact interactions in the compaction process (for example, asphalt concrete)", Colloid Journal, vol. 1, pp. 72-76, 1987.

[2] N.V. Mikhailov, P.A. Rebinder, "On the structural and mechanical properties of dispersed and high-molecular systems", Colloid Journal, vol. 17.2, p. 107, 1955.

[3] S.W.,Goh, Z. You, "Mechanical Properties of Warm Mix Asphalt Using Aspha-min ${ }^{\prime}$, Transportation Research Board 87th Annual Meeting, vol. 1, pp. 53-61, 2008.

[4] K.D. Hall, S.G. Williams, "Establishing variability for construction in Arkansas", Transportation Research Record, vol. 1813, pp. 172-180, 2002.

[5] M.I. Darter, J. Mallela, L. Titus-Glover, C. Rao, G. Larson, A. Gotlif, H. Von Quintus, L. Khazanovich, M. Witczak, M.M. El-Basyouny, S. ElBadawy, A. Zborowski, C.E. Zapata, "Changes to the MechanisticEmpirical Pavement 6: Transportation Design Guide; Software Through Version 0.900", Research Board, vol. 200, p 22, July 2006.

[6] Z. You, W.G. Buttlar, "Micromechanical Modeling Approach to Predict ent Compressive Dynamic Moduli of Asphalt Mixture Using the Distinct Elem arch Method", Transportation Research Record: Journal of the Transportation Rese, vol. 1970, pp, 73-83, 2006. 